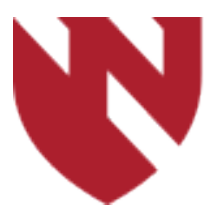

December 2019

\title{
Perceptions of Safety and Support among High School Football Players Utilizing a Helmet Impact Detection System
}

Chris Snyder

University of Nebraska Medical Center

Kailey Snyder

Creighton University

Alyssa Irby

Danae Dinkel

Adam B. Rosen

University of Nebraska at Omaha

Tell us how you used this information in this short survey.

Follow this and additional works at: https://digitalcommons.unmc.edu/gmerj

Part of the Higher Education Commons, and the Psychiatric and Mental Health Commons

\section{Recommended Citation}

Snyder, C., Snyder, K., Irby, A., Dinkel, D., , Rosen, A. B. Perceptions of Safety and Support among High School Football Players Utilizing a Helmet Impact Detection System. Graduate Medical Education Research Journal. 2019 Dec 13; 1(1). https://digitalcommons.unmc.edu/gmerj/vol1/iss $1 / 3$ 


\title{
Perceptions of Safety and Support among High School Football Players Utilizing a Helmet Impact Detection System
}

\begin{abstract}
Background: Concussions are common in high school football athletes and can have short and long-term health impacts. New football helmets furnished with accelerometers to detect rate and location of impact have recently emerged. The use of these helmets offers the ability to rapidly and objectively assess concussions on the sideline. However, minimal research has explored athlete's perceptions of the use of these helmets. Purpose: The purpose of this study was to determine high school football players' perceptions of safety and support following a season of use of a Helmet Impact Detection System. Methods: 118 high school football players from a large parochial school completed an electronic 29-item cross-sectional survey to obtain demographic information and safety perceptions at the end of a football season. Participants wore Riddell InSite Helmets (Riddell, Inc. Elyria, $\mathrm{OH}$ ) the entire football season prior to the survey. Descriptive statistics were computed utilizing SPSS software. Results: When asked to rate the degree to which players felt the concussion helmets helped keep them safe, $69.1 \%$ of students strongly agreed and $23.6 \%$ somewhat agreed. When asked if they agreed or disagreed that they felt safer than opposing teams that did not wear the helmets only $47.3 \%$ of players strongly agreed. When asked if they played harder or more confidently due to the helmets $57.3 \%$ of players strongly agreed. Finally, $17.3 \%$ of players somewhat or strongly agreed that they would not play football if it were not for the helmets. Conclusion: These findings suggest the use of instrumented helmets may encourage athletes' feeling supported by coaches/administrators and their perceptions of safety which could impact their decision to engage in football. However, more research is needed to determine if these feelings of safety translate to a change in rates of concussions compared to players with traditional helmets.
\end{abstract}

\section{Keywords}

Football, Safety, Concussion, High School

\section{Creative Commons License}

\section{c) (i) $\Theta$}

This work is licensed under a Creative Commons Attribution-Noncommercial-No Derivative Works 4.0 License. 


\section{Perceptions of Safety and Support among High School Football Players Utilizing a Helmet Impact Detection System}

Chris Snyder ${ }^{1}$ Kailey Snyder ${ }^{2}$ Alyssa Irby ${ }^{3}$ Danae Dinkel ${ }^{3}$ Adam B. Rosen ${ }^{3}$

${ }^{1}$ University of Nebraska Medical Center, Department of Family Medicine

${ }^{2}$ Creighton University, School of Pharmacy and Health Professions

${ }^{3}$ University of Nebraska at Omaha, School of Health and Kinesiology

https://doi.org/10.32873/unmc.dc.gmerj.1.1.003

\section{Abstract}

Introduction: Concussions are common in high school football athletes and can have short and long-term health impacts. New football helmets furnished with accelerometers that detect rate and location of impact have recently emerged. The use of these helmets offers the ability to rapidly and objectively assess concussions on the sideline. However, minimal research has explored the athletes' perceptions of the use of these helmets. The purpose of this cross-sectional study was to determine high school football players' perceptions of safety and support following a season of use of a Helmet Impact Detection System.

Methods: High school football players $(n=118)$ from a large parochial school completed an electronic 29-item survey to obtain demographic information and safety perceptions at the end of a football season. Participants wore impact detection helmets the entire football season prior to the survey. Descriptive statistics were computed utilizing SPSS software.

Results: When asked to rate the degree to which players felt the concussion helmets helped keep them safe, $69.1 \%$ of students strongly agreed and $23.6 \%$ somewhat agreed. When asked if they agreed or disagreed that they felt safer than opposing teams that did not wear the helmets, only $47.3 \%$ of players strongly agreed. When asked if they played harder or more confidently due to the helmets, $57.3 \%$ of players strongly agreed. Finally, $17.3 \%$ of players somewhat or strongly agreed that they would not play football if it were not for the helmets.

Conclusion: These findings suggest the use of instrumented helmets may encourage athletes' feeling supported by coaches/administrators and their perceptions of safety, which could impact their decision to engage in football. However, more research is needed to determine if these feelings of safety translate to a change in rates of concussions compared to players with traditional helmets.

\section{Introduction}

Concussions account for $9 \%$ of all high school injuries, with the highest incidence in football players at approximately $16 \%$ of injuries reported. ${ }^{1}$ Football has a higher incidence of concussions compared to other sports, as there are often more participants and direct head impacts. ${ }^{2}$ Of particular concern is that high school athletes only report concussion events $40-50 \%$ of the time. ${ }^{3,4}$ The most common reasons provided by athletes for not reporting these events include a lack of concern, fear of removal from competition, and a lack of awareness of the potential for a concussion. ${ }^{4}$ This lack of awareness may stem from players not having appropriate education regarding the symptoms and consequences of concussions, with $25 \%$ of high school football players reporting never receiving any education regarding concussions and their symptoms. ${ }^{5}$ In addition, there is often pressure to continue playing after a head impact and/ or a perceived lack of support from adult stakeholders, potentially delaying evaluation of concussions. ${ }^{6}$

Proper evaluation can improve identification and potentially mitigate the short and longterm effects of concussions. Short-term issues associated with concussions include mild impairments in cognitive processing, headaches, and difficulty performing activities of daily living. ${ }^{4}$ Long-term consequences can include persistent neurocognitive impairments as well as neurodegenerative processes, brain hemorrhage, coma and death. ${ }^{2}$ In light of the severe health concerns associated with concussions, helmets equipped with accelerometers have been developed to alert coaches and athletic trainers when an impact reaches a specific threshold. ${ }^{7}$ Due to the speed of the game and lack of time between plays, the signal provides an objective measure often used in conjunction with concussion protocols.

Commercialized head impact alert systems have become popular to alert clinicians to a blow to the head with the potential to cause a concussion. While there is a fair amount of research to assess the effectiveness of helmet alert systems in detecting head impacts, to the researchers' knowledge there is no research available that investigates athletes' perceptions of safety and coach support while wearing these helmets. ${ }^{8,9,10}$ Assessing athlete's perceptions of safety and support systems with use of these helmets will provide a greater understanding of player needs and concussion protocols associated with helmet impact detection systems. Therefore, the purpose of this study was to determine high school football players' perceptions of safety and support following a season of use of a head impact alert system.

\section{Methods}

During the 2017 football season all players $(n=230)$ of a local parochial high school football program wore impact detection helmets. Following the season, all athletes, regardless of injury or playing status, were e-mailed a link to the survey. This study was approved by the local Institutional Review Board.

The survey consisted of 24 multiple-choice and fill in the blank items pertaining to demographics, perceptions of safety and support, as well as health history and perception. The full survey instrument can be seen in Supplemental Figure 1.

Students were asked to report the following demographic information: year in school, teams on which they played (e.g., freshmen A, freshmen B, junior varsity, varsity), and years of participation in tackle football.

Participants were asked to respond to a series of self-evaluative statements on a 5-point Likert-type scale with a response range from, "strongly disagree" to "strongly agree." Responses to seven statements regarding perceptions of safety and support were obtained.

To measure student's health status all respondents were asked to report yes/no regarding if they: 1) experienced frequent headaches, or 2) been diagnosed by a healthcare professional with a concussion prior to or during this football season. If students reported yes to any of these questions they were then asked to note how often the headaches or concussions occurred. 
In addition, students were provided a previously developed and validated tool known as the Perceived Stress Scale (PSS). The PSS is a widely utilized and accepted tool for measuring stress perceptions and it was designed for use in samples with at least a middle school education making it a reasonable tool for high school athletes. The 10-question scale utilizes a Likert scale with responses ranging from 0 -'never' to 4-'very often.' ${ }^{11}$ Responses were then scored based on the scoring protocol affiliated with the instrument and students were deemed to have low, moderate or high stress. The PSS can be seen in its entirety in Supplemental Figure 2.

\section{Data \& Statistical Analysis:}

General descriptive statistics were used to determine mean response for the statements of safety and support. Spearman's rank order correlations were conducted to determine relationships between perceptions of safety and support and the health and demographic variables. In addition, Spearman rank correlations were utilized to determine if there

\section{Table 1.}

Sociodemographic Variables of Participants. The majority of participants were freshmen with over 2 years of tackle football experience. Half of respondents reported moderate stress levels.

\begin{tabular}{|c|c|}
\hline Characteristic & n (\%) \\
\hline \multicolumn{2}{|l|}{ Year in School } \\
\hline Freshmen & $61(51.6)$ \\
\hline Sophomore & $27(22.8)$ \\
\hline Junior & $14(11.8)$ \\
\hline Senior & $16(13.8)$ \\
\hline \multicolumn{2}{|l|}{ Team Placement } \\
\hline Freshmen & $63(42.0)$ \\
\hline Sophomore & $24(16.0)$ \\
\hline Junior Varsity & $29(19.3)$ \\
\hline Varsity & $34(22.7)$ \\
\hline \multicolumn{2}{|c|}{ Years Playing Tackle Football } \\
\hline 1 year & $20(16.9)$ \\
\hline $2-5$ years & $48(40.6)$ \\
\hline $6-9$ years & $39(33.5)$ \\
\hline 10 years or more & $11(9.3)$ \\
\hline \multicolumn{2}{|l|}{ Stress Level } \\
\hline Low & $51(43.2)$ \\
\hline Moderate & $60(50.8)$ \\
\hline High & $7(5.9)$ \\
\hline \multicolumn{2}{|c|}{ Experience Frequent Headache } \\
\hline Yes & $14(12.2)$ \\
\hline No & $104(87.8)$ \\
\hline \multicolumn{2}{|c|}{ Ever diagnosed with concussion } \\
\hline Yes & $31(26.3)$ \\
\hline No & $87(73.7)$ \\
\hline \multicolumn{2}{|c|}{ Concussions diagnosed before current season } \\
\hline 0 & $89(75.4)$ \\
\hline 1 & $23(19.4)$ \\
\hline 2 & $5(4.2)$ \\
\hline 3 & $1(1.0)$ \\
\hline \multicolumn{2}{|c|}{ Concussions diagnosed current season } \\
\hline 0 & $107(90.6)$ \\
\hline 1 & $9(7.6)$ \\
\hline 2 & $2(1.6)$ \\
\hline
\end{tabular}

were relationships between the statements of safety and support. Statistical significance was set a-priori at $\mathrm{p} \leq 0.05$. Correlational coefficients were interpreted as small $<0.3$, medium $=0.3-0.5$, and large $>0.5 .3 .11$

\section{Results}

Of the 230 players, 118 responded for an overall response rate of $51 \%$. Demographic information for respondents can be found in Table 1. Most players reported playing tackle football for 2-5 years and $26.3 \%$ had experienced a self-reported concussion related injury that had been diagnosed by a healthcare provider.

\section{Perceptions of Safety \& Support:}

In general, players strongly agreed or somewhat agreed with the statements of safety and support (Table 2). The strongest agreement was seen for the statements, 'my coaches care about my safety' (76.4\%) and 'my coaches care about me as a person' $(76.4 \%)$. In addition only $10.9 \%$ of respondents strongly agreed that they would not play football without the newest helmets and safety equipment and $57.3 \%$ agreed they played harder and more confidently because of the trust they had in the equipment, coaches, and athletic trainers to keep them safe.

Furthermore, Spearman's rank order analysis was done to see if these statements had significant relationships with the demographic variables. No significant relationships were found for any of the perception of safety and support statements in regard to history of headaches, history of concussions, number of concussions, number of years playing tackle football, stress level, position on the team, or team level (e.g., junior varsity, varsity). However, year in school did have a significant relationship with the statement, 'I would not play high school football without the newest helmets and safety equipment' $\left(\mathrm{r}_{S}=.55\right.$, $\mathrm{p}<.03$ ). Specifically, being a freshmen was associated with a response of strongly agree or somewhat agree compared to other grade

\section{Table 2.}

Descriptive statistics (\%) of Likert-Type Scale from Perceptions of Safety and Support Survey. The majority of athletes felt somewhat or strongly supported by their school administration, coaches, and equipment to be kept safe on the football field.

\begin{tabular}{|c|c|c|c|c|c|}
\hline Statement & $\begin{array}{l}\text { Strongly } \\
\text { Agree }\end{array}$ & $\begin{array}{l}\text { Somewhat } \\
\text { Agree }\end{array}$ & $\begin{array}{l}\text { Neither } \\
\text { Agree nor } \\
\text { Disagree }\end{array}$ & $\begin{array}{l}\text { Somewhat } \\
\text { Disagree }\end{array}$ & $\begin{array}{l}\text { Strongly } \\
\text { Disagree }\end{array}$ \\
\hline $\begin{array}{l}\text { My school administration cares about my } \\
\text { health as a student-athlete and helps me } \\
\text { obtain my goals. }\end{array}$ & $66.4 \%$ & $27.3 \%$ & $3.6 \%$ & $0.9 \%$ & $0.0 \%$ \\
\hline My coaches care about my safety. & $76.4 \%$ & $19.1 \%$ & $0.9 \%$ & $1.8 \%$ & $0.0 \%$ \\
\hline My coaches care about me as a person. & $76.4 \%$ & $18.2 \%$ & $2.7 \%$ & $0.9 \%$ & $0.0 \%$ \\
\hline $\begin{array}{l}\text { The equipment and helmets provided by } \\
\text { my school keep help me safe. }\end{array}$ & $69.1 \%$ & $23.6 \%$ & $4.5 \%$ & $0.9 \%$ & $0.0 \%$ \\
\hline $\begin{array}{l}\text { Because of my team's equipment I am } \\
\text { safer than my opponents on the football } \\
\text { field. }\end{array}$ & $47.3 \%$ & $38.2 \%$ & $10.9 \%$ & $1.9 \%$ & $0.0 \%$ \\
\hline $\begin{array}{l}\text { I play harder and more confidently } \\
\text { because I trust in the equipment, coaches, } \\
\text { and athletic trainers to keep me safe. }\end{array}$ & $57.3 \%$ & $25.5 \%$ & $10.9 \%$ & $2.7 \%$ & $3.6 \%$ \\
\hline $\begin{array}{l}\text { I would not play high school football } \\
\text { without the newest helmets and safety } \\
\text { equipment.* }\end{array}$ & $10.9 \%$ & $6.4 \%$ & $20.9 \%$ & $20.0 \%$ & $41.8 \%$ \\
\hline
\end{tabular}

*Spearman rank order correlation determined significant differences in responses based on year in school $(p<.03)$ 
levels. Additional descriptive findings can be seen in Table 2.

There were several statements of safety and support that were significantly correlated with one another. Specifically, participants who stated that they strongly agree that their coaches cared about them as a person was associated with strongly agreeing that they played harder and more confidently because they trusted in the equipment, coaches, and athletic trainers to keep them safe $\left(\mathrm{r}_{S}=.45\right.$, $\mathrm{p}<.001)$. In addition, feeling coaches cared about them as a person was related to feeling safer on the football field $\left(\mathrm{r}_{S}=.57, \mathrm{p}<.001\right)$.

Finally, believing their school administration cared about their health as a student athlete $\left(\mathrm{r}_{S}=.45, \mathrm{p}<.001\right)$ and believing their equipment made them safer than their opponents on the football field $\left(\mathrm{r}_{s}=.41, \mathrm{p}<\right.$ $.001)$ was related to playing harder and more confidently because of the trust put in the equipment, coaches, and athletic trainers of their school. Additional findings can be seen in Table 3.

\section{Discussion}

The results of this study suggest players utilizing a helmet impact detection system have positive perceptions of safety and support. Further, these perceptions do not vary based on demographic or health-related variables, with the exception of freshmen students being more likely to report they would not play football if it weren't for the use of the helmet impact detection system. In general $17.3 \%$ of players, mostly freshmen, agreed or strongly agreed they would not play without the impact detection helmets. This finding aligns with the trend of disengagement in tackle football that is being seen on an international scale. ${ }^{12}$ It also suggests that putting additional resources towards player safety such as helmet impact detection systems might support continued engagement in high school football.

Importantly, coaches were found to influence players' perceptions of safety. When a player felt their coach cared for them, they reported greater feelings of safety while on the field. This aligns with findings in healthcare literature that suggest effective patient provider relationships elicit positive outcomes. ${ }^{13}$ For example, positive relationships and interactions between patients and providers results in increased adherence to medical recommendations and greater self-care. ${ }^{13}$ Our findings suggest similar trends in the high school coach/athlete relationship. A more supportive coach that allows athletes to feel safer during play could also lead to athletes being more engaged in their own selfcare and recognizing concussion symptoms or health issues earlier on. This has previously been seen at the college level. In a study evaluating college football athletes, high levels of perceived coach support were linked to fewer undiagnosed concussions. ${ }^{14}$ However, further investigation is needed to explore the coach/athlete relationship at the high school level.

Our findings also suggest athletes that feel safer on the field report playing harder and more confidently. This is similar to findings in a workforce study, which found perceptions of safety by employees were associated with greater employee productivity. ${ }^{15}$ Although this is extremely beneficial for the employee/ employer relationship, more research is needed to ensure benefit to the athlete/ coach dynamic. Specifically, it needs to be determined whether these reports of playing harder and more confidently are not resulting in greater injury to the player. The role of the coach should also be explored more in-depth.

Table 3.

Spearman's rank order analysis determined feeling a coach cared about the athlete as a person was significantly related to playing harder and more confidently $(p<.05)$ as well as feeling safer on the football field $(p<.001)$.

\begin{tabular}{|c|c|c|c|c|c|c|c|}
\hline & $\begin{array}{c}\text { My } \\
\text { administration } \\
\text { cares about } \\
\text { my health as a } \\
\text { student-athlete } \\
\text { and helps me } \\
\text { obtain my goals }\end{array}$ & $\begin{array}{l}\text { My coaches care } \\
\text { about my safety }\end{array}$ & $\begin{array}{l}\text { My coaches care } \\
\text { about me as a } \\
\text { person }\end{array}$ & $\begin{array}{l}\text { Because of our } \\
\text { equipment I am } \\
\text { safer than my } \\
\text { opponents on } \\
\text { the football field }\end{array}$ & $\begin{array}{l}\text { The equipment } \\
\text { and helmets } \\
\text { provided by my } \\
\text { school help keep } \\
\text { me safe }\end{array}$ & $\begin{array}{l}\text { I play harder and } \\
\text { more confidently } \\
\text { because I trust in } \\
\text { the equipment, } \\
\text { coaches, and } \\
\text { athletic trainers } \\
\text { to keep me safe }\end{array}$ & $\begin{array}{l}\text { I would not } \\
\text { play football } \\
\text { without the } \\
\text { newest helmets } \\
\text { and safety } \\
\text { equipment }\end{array}$ \\
\hline $\begin{array}{l}\text { My administration cares about } \\
\text { my health as a student-athlete } \\
\text { and helps me obtain my goals }\end{array}$ & 1.000 & $0.559^{* *}$ & $0.331^{* *}$ & $0.259^{* *}$ & $0.200^{*}$ & $0.450^{* *}$ & -0.040 \\
\hline $\begin{array}{l}\text { My coaches care about my } \\
\text { safety }\end{array}$ & $0.559^{* *}$ & 1.000 & $0.574^{\star *}$ & 0.168 & 0.177 & $0.394^{* *}$ & -0.033 \\
\hline $\begin{array}{l}\text { My coaches care about me as } \\
\text { a person }\end{array}$ & $0.331^{* *}$ & $0.574^{\star *}$ & 1.000 & $0.224^{*}$ & $0.226^{*}$ & $0.292^{* *}$ & 0.188 \\
\hline $\begin{array}{l}\text { Because of our equipment I } \\
\text { am safer than my opponents } \\
\text { on the football field }\end{array}$ & $0.259^{\star *}$ & 0.168 & $0.224^{*}$ & 1.000 & $0.489^{\star *}$ & $0.410^{* *}$ & 0.158 \\
\hline $\begin{array}{l}\text { The equipment and helmets } \\
\text { provided keep help me safe }\end{array}$ & $0.200^{*}$ & 0.177 & $0.226^{*}$ & $0.489^{* *}$ & 1.000 & $0.297^{* *}$ & 0.124 \\
\hline $\begin{array}{l}\text { I play harder and more } \\
\text { confidently because I trust } \\
\text { in the equipment, coaches, } \\
\text { and athletic trainers to keep } \\
\text { me safe }\end{array}$ & $0.450^{* *}$ & $0.394^{* *}$ & $0.292^{\star *}$ & $0.410^{\star *}$ & $0.297^{\star *}$ & 1.000 & 0.081 \\
\hline $\begin{array}{l}\text { I would not play high school } \\
\text { football without the newest } \\
\text { helmets and safety equipment }\end{array}$ & -0.040 & -0.033 & 0.188 & 0.158 & 0.124 & 0.081 & 1.000 \\
\hline
\end{tabular}


Research has shown coaching behavior and knowledge of concussion symptoms influences how coaches communicate health and safety information. ${ }^{16,17}$

Finally, although our study did not find any relationship between perceptions of stress and concussion incidence, relationships between stress and injury have been seen in college athletes. Specifically, college football players were more likely to get injured during times of high academic stress. ${ }^{18}$ Our findings may indicate that high school students either do not experience the same levels of stress as college students and/or their stress is unrelated to injuries. However, as this study only examined concussion related injuries, further exploration should be done at the high school

\section{References}

1 Gessel LM, Fields SK, Collins CL, Dick RW, Comstock RD. Concussions among United States high school and collegiate athletes. Journal of Athletic Training, 2007; 42, 495-503.

2 Rowson, S, Duma, SM, Beckwith, JG, Chu, JJ, Greenwald, RM, Crisco, JJ, Brolinson, PG, Duhaime, AC, McAllister, TW, Maerlender, AC. Rotational head kinematics in football impacts: an injury risk function for concussion. Annals of Biomedical Engineering, 2012; 40:1.

3 Johna K. Register-Mihalik, Kevin M. Guskiewicz, Tamara C. Valovich McLeod, Laura A. Linnan, Frederick O. Mueller, and Stephen W. Marshall. Knowledge, Attitude, and Concussion-Reporting Behaviors Among High School Athletes: A Preliminary Study. Journal of Athletic Training: 2013;48(5): 645-653.

4 McCrea, M, Hammeke, T, Olsen, G, Leo, P, Guskiewicz, K. Unreported concussion in high school football players: implications for prevention. Clinical Journal of Sports Medicine. 2004; 14(1); 13-17.

5 Cournoyer, J, Tripp, BL. Concussion Knowledge in High School Football Players. Journal of Athletic Training. 2014; 49(5), 654-658.

6 Kroshus, EM, Baugh, CM, Hawrilenko, MJ, Daneshvar, DH. Determinants of coach communication about concussion safety in U.S. collegiate sport. Annals of Behavioral Medicine. 2015; 48: 532-541. level to examine the relationship between stress and all football related injuries.

This study was limited by its retrospective survey design, meaning players completed the survey at the end of the football season. Having the players' complete multiple surveys throughout the season could have elicited different findings, especially in regard to stress perceptions as stress varies. The study was limited by the relatively small sample size and the use of a parochial school may not allow for generalizability of findings to athletes attending non-parochial schools. This study was strengthened by its use of a validated measure to assess stress and by having a team of experts in diverse fields assisting with survey development.

7 Grant L. Iverson, Brian L. Brooks, Michael W. Collins, Mark R. Lovell. Tracking neuropsychological recovery following concussion in sport, Brain Injury, 2006; 20:3, 245-252

8 Greenwald RM, Gwin JT, Chu JJ, Crisco JJ. Head Impact Severity Measures for Evaluating Mild Traumatic Brain Injury Risk Exposure. Neurosurgery. 2008; 62(4):789-798

9 Mihalik JP, Lynall RC, Wasserman EB, et al. Evaluating the "Threshold Theory": Can Head Impact Indicators Help? Medicine \& Science in Sports \& Exercise. 2017; 247-243.

10 Schmidt, JD, Guskiewicz, KM, Mihalik, JP, Blackburn, JT, Siegmund, GP, \& Marshall, SW Head impact magnitude in American high school football. Pediatrics. 2016; 138(2), 1-9.

11 Cohen J. Statistical power analysis for the behavioral sciences 2nd ed. Hillsdale, N.J.: L. Erlbaum Associates. 1988.

12 National Federation of State High School Associations Participation statistics 2009-2018. https://www.nfhs. org/ParticipationStatistics/ParticipationStatistics/ Accessed Dec. 10, 2018.

13 Street, RL, Makoul, G, Arora, NK, Epstein, RM. How does communication heal? Pathways linking clinicianpatient communication to health outcomes. Patient Education and Counseling. 2009; 74(3); 295-301.

\section{Conclusion}

To our knowledge this was the first study to examine high school athletes' perceptions of safety and support after a season of utilizing a helmet impact detection system. These findings suggest the use of impact detection helmets may enhance athletes' feeling of support from coaches/administrators and their perceptions of safety, which could impact their decision to engage in football. Further, students that feel safer appear to be playing harder and more confidently on the field. However, more research is needed with the inclusion of non-parochial student athletes to confirm findings and determine if this confidence is resulting in additional injuries.

14 Baugh CM, Kroshus E, Daneshvar DH, \& Stern RA. Perceived Coach Support and Concussion SymptomReporting: Differences between Freshmen and NonFreshmen College Football Players. The Journal of Law, Medicine \& Ethics. 2014; 42(3), 314-322.

15 Jiang L, Probst TM. The relationship between safetyproduction conflict and employee safety outcomes: Testing the impact of multiple organizational climates Work \& Stress. 2015; 29:2, 171-189,

16 Kroshus E, Garnett B, Hawrilenko M, Baugh CM, Calzo JP. Concussion under reporting and pressure from coaches, teammates, fans, and parents. Social Science and Medicine. 2015; 134; 66-75.

17 Malinauskas R. College athletes' perceptions of social support provided by their coach before injury and afte it. Journal of Sports Medicine Physical Fitness. 2008; 48(1); 107-12.

18 Mann JB, Bryant KR, Johnstone B, Ivey PA, Sayers SP. Effect of physical and academic stress on illness and injury in division 1 college football players. The Journal of Strength \& Conditioning Research. 2016; $30(1), 20-25$. 